\title{
Optimizing the Effect of Coconut Shell/Zeolite Adsorbent Blend for Treatment 敬隻 of Oilfield Produced Water
}

\author{
Camillus U Okonkwo ${ }^{1 \#}$, Bright 0 Okonkwo ${ }^{2 *^{*}}$, Sylvester Uwadiae ${ }^{1 *}$ and Chigoziri Njoku ${ }^{3,4}$
}

${ }^{1}$ Department of Chemical Engineering, University of Benin, Nigeria

${ }^{2}$ Department of Nuclear and Quantum Engineering, Korea Advanced Institute of Science and Technology, Korea

${ }^{3}$ Department of Chemical Engineering, Federal University of Technology, Nigeria

${ }^{4}$ Africa Centre of Excellence in Future Energies and Electrochemical System (ACE-FUELS), Federal University of Technology, Nigeria

Submission: February 14, 2022; Published: March 02, 2022

*Corresponding author: Bright 0 Okonkwo, Department of Nuclear and Quantum Engineering, Korea Advanced Institute of Science and Technology, Daejeon, Korea

Sylvester Uwadiae, Department of Chemical Engineering, University of Benin, Benin City, Nigeria

\#Authors equally contributed

\section{Abstract}

In this study, the adsorption capacity of the adsorbent blend of coconut shell activated carbon and zeolite on the removal of total organic carbon (TOC) and total suspended solids (TSS) from oilfield produced water were investigated. The maximum amounts of TOC adsorbed via experiment and prediction are $148.87 \mathrm{mg} . \mathrm{g}^{-1}$ and $150.020 \mathrm{mg}_{\mathrm{g}} \mathrm{g}^{-1}$, respectively. The experimental value of maximum TOC adsorbed was obtained at an adsorbent dosage of $0.99 \mathrm{~g}$ zeolite $(0.01 \mathrm{CSAC})$, contact time of $180 \mathrm{mins}$ and temperature of $40^{\circ} \mathrm{C}$, while the maximum amount of TSS adsorbed via experiement and prediction are $1.76 \mathrm{mg} . \mathrm{g}^{-1}$ and $1.579 \mathrm{mg}^{-1} \mathrm{~g}^{-1}$, respectively. Also, the experiemental value of the maximum TSS was obtained at an adsorbent dosage of 0.99g.ZA ( $0.01 \mathrm{CSAC}$ ), contact time of $180 \mathrm{mins}$ and temperature of $40^{\circ} \mathrm{C}$. The high and close R-squared values of the experimental and predicted values of the TOC ( 0.9638 and 0.8851 , respectively) and TSS ( 0.9755 and 0.9072 , respectively) adsorption indicates that the experimental data is in reasonable agreement with the predicted data, and hence showed the effectiveness of response surface methodology in modeling the adsorption of TOC and TSS from produced water. The high amounts of TOC and TSS adsorbed indicates that the adsorbent blend of coconut shell and zeolite is effective and efficient in the treatment of waste water streams laden with high concentrations of TOC and TSS.

Keywords: Produced water; Adsorbent; SEM; XRD; Treatment; TOC

Highlights

a) The adsorption capacity of the adsorbent blend of CSAC/ zeolite was high.

b) The adsorbent blend had a high crystalline structure.

c) RSM modeling method was effective in predicting the total amount of TOC and TSS adsorbed.

d) A quadratic model was developed in this study.

Graphical Abstract

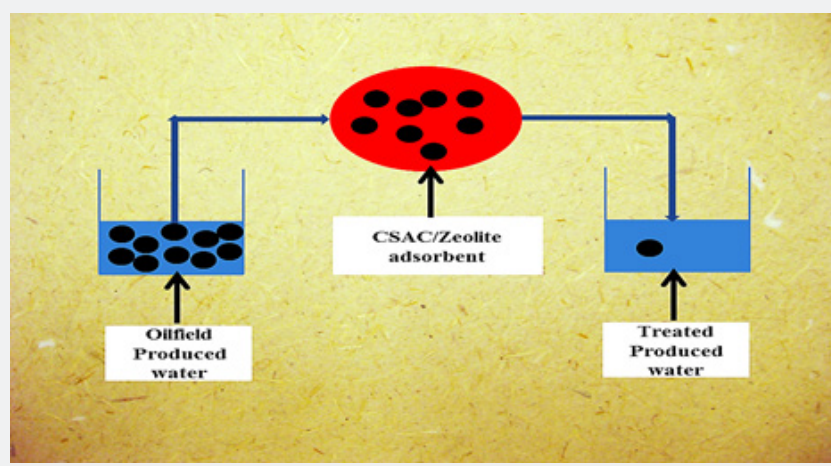

Graphical Abstract 


\section{Introduction}

Industrial processes sometimes produce industrial effluents that contaminate water bodies, and its effect has risen as a significant problem in sparsely and thickly populated nations [1]. Estuaries and inland water bodies which are significant sources of drinking water in developing nations are often contaminated by the activities of the adjoining population and industrial establishments [2]. River systems are the primary means of waste disposal especially effluents from industries near them. These effluents from industries have a great deal of influence on pollution of water body and can alter the physical, chemical and biological nature of the accepting water body $[3,4]$. Some of these industrial processes include organic chemical production, food processing, iron and steel production, mines and quarries, petroleum refining and petrochemical plants operations, and oil and gas exploration/production operations, which has "produced water" as its major waste.

In the oil and gas industry in specific, oilfield releases water which is the water that comes back to the surface from oil or gas well [5] and represents the biggest volume of waste stream in oil and gas productions on most offshore platforms [6,7]. When the oilfield well begins to create a huge quantity of oil and gas, the blended fluid stream spilling out of the well comprises of oil, gas, and wastewater. This wastewater which is ordinarily referred to as produced water is isolated at the surface $[5,8,9]$. The produced water generated throughout the life of a well is generally thought to be a combination of the fluid used to fracture the well and formation water that resided in either the target formation or neighbouring formations [5]. The constituents of produced water are comprehensively classified into organic and inorganic substances which contain dissolved and dispersed oils, grease, heavy metals, treatment chemicals and formation solids, dissolved gases, scale products, microorganisms and dissolved oxygen $[8,10,11]$. It is evaluated that all-inclusive, more than seventy billion barrels of produced water is generated by the petrochemical industries yearly [8,12]. This Produced water will regularly keep on being produced and isolated from the recovered oil and gas products, in this way producing a nonstop wastewater stream throughout the duration of the well. Since water is turning into a major issue in some parched territories and as guidelines become progressively prohibitive for disposal and reinjection, produced water reuse/recycle will be a solution to reduce the wastewater production and alleviate environmental effects [13]. Significant effort is being made to create economic strategies to treat produced water, the majority of which is very salty, and put it to other uses [5].

Numerous advancements that have been created for the treatment and cleansing of wastewater include chemical precipitation, solvent extraction, dialysis/electro dialysis, electrolyte extraction, reverse osmosis, ion exchange, evaporation, adsorption, filtration, air stripping, flocculation and soil flushing/ washing chelation [14]. In any case, most of these methods are not broadly utilized because they are costly and low plausibility for small-scale applications [15]. Adsorption technique has demonstrated to be a productive and savvy among every one of the methods [16]. Adsorption is one of the viable and appropriate procedures for the treatment of contaminant from wastewater as it is generally utilized in water pollution control where activated carbon is utilized as the adsorbent because of its high surface area and pore volume as well as inert properties. In light of both environmental and the economic perspectives, exceptional consideration has been centered around the utilization of natural adsorbents gotten from natural materials and waste agricultural products as an alternative to replacing commercially activated carbon (artificial adsorbents), however, artificial adsorbents are still in use to date. Low-cost natural material or certain waste from an industrial or agricultural operation is one of the resources for low-cost adsorbents and has seen strong interest by researchers in replacing the conventional activated carbon [17] recently.

Kurniawan \& Babel [18], carried out a research study on $\mathrm{Cr}(\mathrm{VI})$ removal from contaminated wastewater using low-cost adsorbents and commercial activated carbon (CAC). In their study, the technical feasibility of using coconut shell carbon (CSC), zeolite, and CAC for chromium removal from contaminated wastewater was investigated using batch studies at varying chromium concentrations $(5,10,20$, and $25 \mathrm{mg} / \mathrm{l})$. From their results, it was evident that between the two low-cost adsorbents, CSC has a higher chromium removal capability $(2.18 \mathrm{mg} / \mathrm{g})$ than zeolite $(1.79 \mathrm{mg} / \mathrm{g})$, while CAC demonstrated an outstanding adsorption capacity (4.72mg/g). According to Rojas-Mayorga et al. [19], the process efficiency and operational costs of an adsorption process highly depend on the characteristics of the adsorbent, especially its porous structure, and surface chemistry [19]. Based on these viewpoints, this study focuses on the effect of both blends of natural (coconut shell) and artificial (zeolite) adsorbent on the treatment of produced water, with a view of providing insightful data and information on the adsorption capacity of natural/ artificial blend of adsorbents for the treatment of effluent streams laden with contaminants. A good understanding of the process will yield optimum adsorption efficiency of the adsorbent blend and provide necessary information for the petroleum industry on their liquid discharge management in order to abide by environmental protection laws and regulations.

In this study, the synergistic effects of coconut shell and zeolite adsorbents in the treatment of produced water were studied with several analytical tools. Response surface methodology (RSM), which is a statistical tool was employed to study the interactions of process variables, optimize the number of conductivity components adsorbed by the activated carbon produced from coconut shells, and model the relationship between the number of impurities adsorbed by the adsorbent and the process conditions which are adsorbent dosage (zeolite/coconut composite), contact time and temperature. The characterization of the zeolite/ coconut shell char composite was carried out using several 
analytical tools such as scanning electron microscopy (SEM), $\mathrm{X}$-ray diffraction (XRD) techniques, Fourier transform infra-red (FTIR), X-ray fluorescence (XRF) and Brunauer-Emmett-Teller (BET) instrument.

\section{Experimental}

\section{Materials}

Coconut shells were bought at Uselu Market, Benin City, Edo State, Nigeria and pre-treated before further use. Zeolite adsorbent (ZA) was purchased from a local chemical store. The effluent waste (produced water) was obtained from Pan Ocean (an international oil and gas company) flow station in Umutu, Delta State, Nigeria.

\section{Methodology}

\section{Collection of effluent samples}

Effluent points of discharge were collected using a fetcher. All samples were collected in a thoroughly cleaned 5-liter polyethylene bottles tightly closed with information tags for identification. Each bottle was rinsed with the appropriate sample and re-rinsed with the surface water before the final sample collection. The samples were placed in a cooler box at $4^{\circ} \mathrm{C}$ and then taken to the laboratory for analysis.

\section{Analyses of physicochemical parameters of effluent}

Oilfield Produced water (effluent) was characterized for $\mathrm{pH}$, total organic carbon (TOC), conductivity, total suspended solids (TSS), total dissolved solids (TDS), total solid (TS), chemical oxygen demand (COD), dissolve oxygen (DO), and electrical conductivity (EC) contents before treatment with the activated carbon/zeolite. The ASTM standard procedures [20] for these tests were employed.

\section{Preparation of coconut shell activated carbon (CSAC)}

The coconut shell char was prepared using previously described method [21,22]. The coconut shells before and after carbonization is depicted in Figure 1.
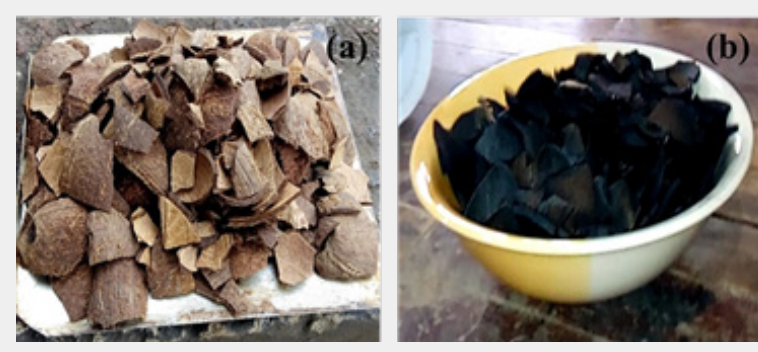

Figure 1: Activated carbon preparation (a) coconut shells (b) carbonized coconut shells.

\section{Synthesis of ZA/CSAC composite}

The synthesis of the adsorbent blend was carried out by using pre-existing method [22] described afterward. ZA was used as the composite material for the CSAC. Firstly, a gel solution of the ZA was prepared; the CSAC was added to the solution and mixed thoroughly. The amount of CSAC in the composite adsorbent was varied from 0.01 to $0.99 \mathrm{~g}$ according to the design of the experiment given in Table 1. The final solution was dried on petri-dish for $24 \mathrm{~h}$ at room temperature to form Qsmall pellets which were stored in airtight bottles for further analysis.

Table 1: Range of values for adsorption experiments.

\begin{tabular}{|c|c|c|c|c|c|c|}
\hline \multirow{2}{*}{ Factors } & \multirow{2}{*}{ Coding } & \multicolumn{5}{|c|}{ Coded and Actual Range of Values } \\
\cline { 3 - 7 } & & $-\boldsymbol{\alpha}$ & $\mathbf{- 1}$ & $\mathbf{0}$ & $\mathbf{1}$ & $\mathbf{+}$ \\
\hline Proportion of zeolite in CSAC & $\mathrm{A}$ & 0.01 & 0.2 & 0.5 & 0.8 & 280 \\
\hline Contact time $(\mathrm{mins})$ & $\mathrm{B}$ & 12 & 80 & 180 & 49 & 348 \\
\hline Temperature $\left({ }^{\circ} \mathrm{C}\right)$ & $\mathrm{C}$ & 26 & 32 & 40 & 54 \\
\hline
\end{tabular}

\section{Determination of point of zero charge}

The point of zero charges (pzc), $\mathrm{pH}_{-\mathrm{Pzc}}$ was determined by the mass titrations (MT) method described by Fiol \& Villaescusa [23]. Different masses of sorbent within the concentration range $5-100 \mathrm{~g} / \mathrm{L}$ were put into contact with a $0.03 \mathrm{M} \mathrm{KNO}_{3}$ solution. The aqueous suspensions were agitated for $24 \mathrm{~h}$ in a shaker at $250 \mathrm{rpm}$ until equilibrium $\mathrm{pH}$ was reached. The $\mathrm{pH}-\mathrm{pzc}$ is the $\mathrm{pH}$ at which a plateau is achieved when plotting equilibrium $\mathrm{pH}$ versus sorbent mass.

\section{Characterization of CSAC}

The functional groups present in the CSAC were analyzed using a Fourier transform infrared (FTIR Machine, Cary 630, Agilent Technologies) within the wavelength region of 4000 to 
$650 \mathrm{~cm} \cdot \mathrm{K}^{-1}$. CSAC was used in the form of Potassium Bromide (KBr) discs which were prepared by grinding $1 \mathrm{mg}$ sample $/ 100 \mathrm{mg}$ predried KBR. X-ray fluorescence, XRF spectroscopy (XRF machine, Genius 1F, XeneMatrix) was used to obtain the elemental chemical compositions of the CSAC before uptake the uptake studies for more precise measurement. While, X-ray diffractometer, XRD (XRD machine, Rigaku Miniflex) was used to measure the crystalline phase of the CSAC before batch adsorption. JCPDS (Joint Committee of the Powder Diffraction Standard) was used to identify the phases present in the adsorbent sample. The surface morphology of the adsorbent sample was examined with scanning electron microscope equipped with energy dispersive X-ray spectroscopy device (SEM/EDX, FEI XL30).

\section{Treatment of produced water}

The produced water was treated using the adsorbent blend of ZA and CSAC by Batch adsorption technique. In this technique as described elsewhere $[24,25]$, exactly $200 \mathrm{ml}$ of produced water was measured into polythene bottles and $10 \mathrm{~g}$ of the adsorbent blends were transferred into these bottles. The mixtures in polythene bottles were agitated at the same time with a basic reciprocating shaker at 200rpm for the various contact times given according to the experimental design in Table 1 and left undisturbed on the desk for $24 \mathrm{~h}$ to allow the system to equilibrate after which the mixture was filtered through a Whatmann filter paper into another $100 \mathrm{~cm}^{3}$ polyethylene bottle. The concentrations of the residual or remaining TOC in the filtrate after the adsorption process were determined using the TOC analyzer described by Chen et al. [26]. The uptake of TSS and TOC by the adsorbent was calculated using Eq.1:

$$
q=\frac{V\left(C_{o}-C_{f}\right)}{m}
$$

Where $\mathrm{q}$ is the amount of TOC and TSS adsorbed in milligram per gram of the adsorbent, $\mathrm{C}_{\mathrm{o}}$ is the initial concentration of the TOC and TSS before the adsorption process, $\mathrm{C}_{\mathrm{f}}$ is the final concentration of the TOC and TSS in the filtrate after the adsorption process, $\mathrm{m}$ is the mass of the adsorbent and V is the volume of the solution in $\mathrm{cm}^{3}$.

\section{Design of experiment}

The adsorption of the heavy metals by the adsorbent blends was done using the optimal central composite design (CCD) of experiment. The variables considered and their ranges of values are given in Table 1. The amounts of TOC and TSS adsorbed in mg.g${ }^{1}$ of composite adsorbent were taken as the response variables. The experimental design matrix showing the combination of factorial variables is presented in Table 2 .

Table 2: Experimental design matrix for adsorption experiment.

\begin{tabular}{|c|c|c|c|c|c|c|c|}
\hline \multirow{2}{*}{ Std. Order } & \multirow{2}{*}{ Run Order } & \multicolumn{3}{|c|}{ Coded Factors } & \multicolumn{3}{|c|}{ Actual Factors } \\
\hline & & $\mathbf{A}$ & B & C & Proportion of Zeolite in CSAC & Contact Time (mins) & Temperature $\left({ }^{\circ} \mathrm{C}\right)$ \\
\hline 1 & 1 & -1 & -1 & -1 & 0.2 & 80 & 32 \\
\hline 2 & 17 & 1 & -1 & -1 & 0.8 & 80 & 32 \\
\hline 3 & 8 & -1 & 1 & -1 & 0.2 & 280 & 32 \\
\hline 4 & 12 & 1 & 1 & -1 & 0.8 & 280 & 32 \\
\hline 5 & 13 & -1 & -1 & 1 & 0.2 & 80 & 48 \\
\hline 6 & 10 & 1 & -1 & 1 & 0.8 & 80 & 48 \\
\hline 7 & 15 & -1 & 1 & 1 & 0.2 & 280 & 48 \\
\hline 8 & 9 & 1 & 1 & 1 & 0.8 & 280 & 48 \\
\hline 9 & 14 & -1.68 & 0 & 0 & 0.01 & 180 & 40 \\
\hline 10 & 4 & 1.68 & 0 & 0 & 0.99 & 180 & 40 \\
\hline 11 & 11 & 0 & -1.68 & 0 & 0.5 & 12 & 40 \\
\hline 12 & 7 & 0 & 1.68 & 0 & 0.5 & 348 & 40 \\
\hline 13 & 18 & 0 & 0 & -1.68 & 0.5 & 180 & 26 \\
\hline 14 & 20 & 0 & 0 & 1.68 & 0.5 & 180 & 54 \\
\hline 15 & 2 & 0 & 0 & 0 & 0.5 & 180 & 40 \\
\hline 16 & 5 & 0 & 0 & 0 & 0.5 & 180 & 40 \\
\hline 17 & 16 & 0 & 0 & 0 & 0.5 & 180 & 40 \\
\hline 18 & 19 & 0 & 0 & 0 & 0.5 & 180 & 40 \\
\hline 19 & 3 & 0 & 0 & 0 & 0.5 & 180 & 40 \\
\hline 20 & 6 & 0 & 0 & 0 & 0.5 & 180 & 40 \\
\hline
\end{tabular}




\section{Statistical analysis}

The experimental data were analyzed according to the regression procedure to fit the polynomial equation in which the level of significance ( $p$-value) of all coefficients was $<0.05$. Based on experimental data shown in Table 2, the regression coefficient was determined by the statistical software package Designexpert $^{\circledR}$ (Version 11; stat-ease, Inc., Minneapolis, USA) to predict the process response as a function of independent variables and their interactions were used to understand the system behaviour. The coded values of the process parameters were determined by the expression given in Eq.2:

$$
x_{i}=\frac{X_{i}-X_{0}}{\Delta X}
$$

where $\mathrm{x}_{\mathrm{i}}$ is the coded value of the ith variable, $\mathrm{X}_{\mathrm{i}}$ is the uncoded value of the ith test variable, and $X_{o}$ is the uncoded value of the ith test variable at centre point. The mathematical relationship between the process variables and response was calculated by the following quadratic polynomial expression in Eq. 3:

$$
Y=\beta_{0}+\sum_{i=1}^{n} \beta_{i} x_{i}+\sum_{i=1}^{n} \beta_{i i} x_{i}^{2}+\sum_{i=1}^{n} \sum_{j>1}^{n} \beta_{i j} x_{i} x_{j}
$$

where $Y$ is the response, $X_{\mathrm{i}}$ and $X_{\mathrm{j}}$ represent the independent variables, $\beta_{0}$ is constant, $\beta_{\mathrm{i}}$ is linear term coefficient, $\beta_{\mathrm{ii}}$ is the quadratic term coefficient, $\beta_{\mathrm{ij}}$ is cross-term coefficient and ' $n$ ' is the number of process variables studied and optimized during the study. Analysis of variance (ANOVA) was carried out to estimate the effects of process variables and their possible interaction effects on the maximum ethanol yield in the response surface regression procedure. The goodness and best fit of the model was evaluated by a regression coefficient $R^{2}$. The response surface and contour plots are obtained using the fitted polynomial equation generated from regression analysis by keeping one of the independent variables at the center value $(0)$.

\section{Results and Discussion}

\section{Physicochemical properties of the studied produced water}

The TOC, COD, DO, EC, TDS, TSS and TS of produced water used in this study were $3590 \mathrm{mg} / \mathrm{l} .6 .08 \mathrm{mg} / \mathrm{l}, 13.65 \mathrm{mg} / \mathrm{l}, 5.53 \mathrm{mg} / \mathrm{l}$, $0.2765 \mathrm{mg} / \mathrm{l}, 52.34 \mathrm{mg} / \mathrm{l}$, and $52.6165 \mathrm{mg} / \mathrm{l}$ respectively. The TOC value of $3590 \mathrm{mg} / \mathrm{l}$ as obtained in this study is within the range of 0.1 to $11,000 \mathrm{mg} / \mathrm{l}$ given for typical TOC value of produced water [27]. The COD and TDS of 6.08 and $\sim 0.28 \mathrm{mg} / \mathrm{l}$ respectively were within the department of petroleum resources (DPR) of Nigeria permissible limits of 125 and $5000 \mathrm{mg} / \mathrm{l}$ respectively for discharged water [28]. However, the TSS value of the produced water of $52.34 \mathrm{mg} / \mathrm{l}$ is higher than the maximum permissible limit of $35 \mathrm{mg} / \mathrm{l}$ set by DPR for effluent discharged into surface water courses. Furthermore, the EC test which is a measure of the saltiness of the water with a measurement of 0 to $50,000 \mu \mathrm{S} /$ $\mathrm{cm}$, was observed to be $5.53 \mu \mathrm{S} / \mathrm{cm}$ in this study. Based on known standard, the EC value of freshwater is usually between 0 and $1,500 \mu \mathrm{S} / \mathrm{cm}$, and that of typical sea water has a conductivity value of about $50,000 \mu \mathrm{S} / \mathrm{cm}$ [29]. Also, it is known that when salts value reaches high levels in freshwater it can cause problems for aquatic ecosystems and complicated human uses [29], therefore, it is imperative that low level of salts are found or maintained in natural waterways. The EC value of $5.53 \mu \mathrm{S} / \mathrm{cm}$ obtained in this study shows that the produced water is safe for discharged into water bodies in this regards.

\section{$\mathrm{pH}$ at point of zero charge $\left(\mathrm{pH}_{\mathrm{PZC}}\right)$ of adsorbent}

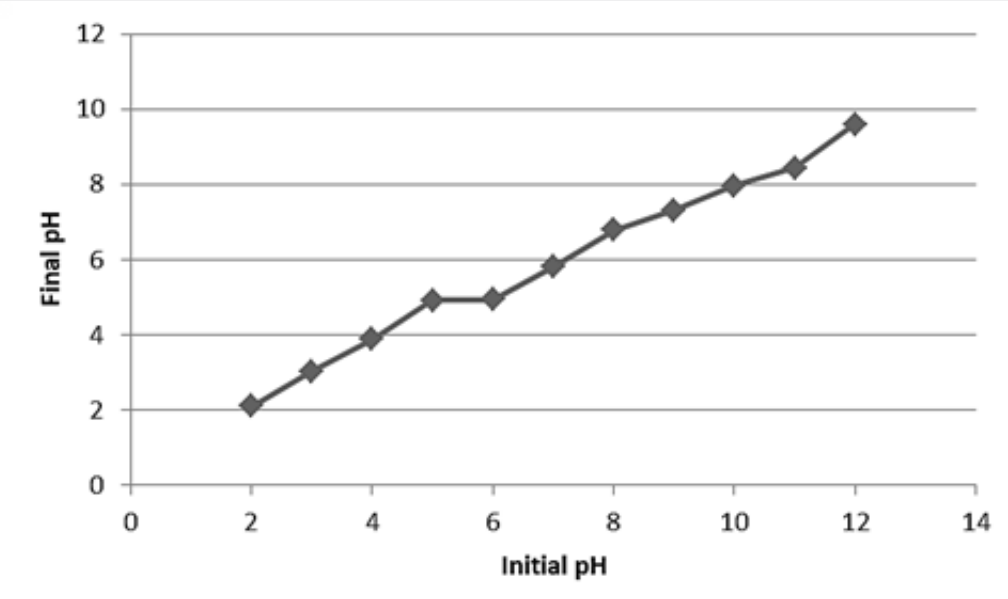

Figure 2: Initial and final $\mathrm{pH}$ of adsorbent (CSAC).

Figure 2 presents a plot for the determination of point of zero charge of the adsorbent. The curve shows that the $\mathrm{pH}^{-}{ }_{\mathrm{PZC}}$ is approximately 4.9. At $\mathrm{pH}$ greater than 4.9 , the adsorbent has predominantly a negative charge at the surface, while below 
this value the surface is positively charged. According to some literature [30], the $\mathrm{pH}$ at the point of zero charge on activated carbon is close to 7.0. However, this behaviour was not observed for the adsorbent used in this study. The value obtained (4.9) can be explained by the acid treatment to which the activated carbon was subjected prior to use, since the $\mathrm{H}^{+}$ions present on the surface after treatment will be released into the solution, lowering the $\mathrm{pH}$ [31]. The adsorption of cations, such as metal ions, is favored at $\mathrm{pH}>\mathrm{pH}_{\mathrm{PZC}^{\prime}}$, while the adsorption of anions is favored at $\mathrm{pH}<$ $\mathrm{pH}^{\mathrm{PZC}^{\prime}}{ }$ due to electrostatic repulsion [31]. Thus, the TOC and TSS adsorption process should be carried out at $\mathrm{pH}$ equal to or greater than 4.9 .

\section{Characterization of adsorbent}

\section{FTIR analysis}

Figure 3 shows the functional groups of the adsorbent as given by FTIR analysis, and its interpretation is given in Table 3. From Table 3 it is seen that a weak absorption band of alkynes, nitriles, quartz were observed, while a fairly strong band of alkenes and ester anhydride were noticed.

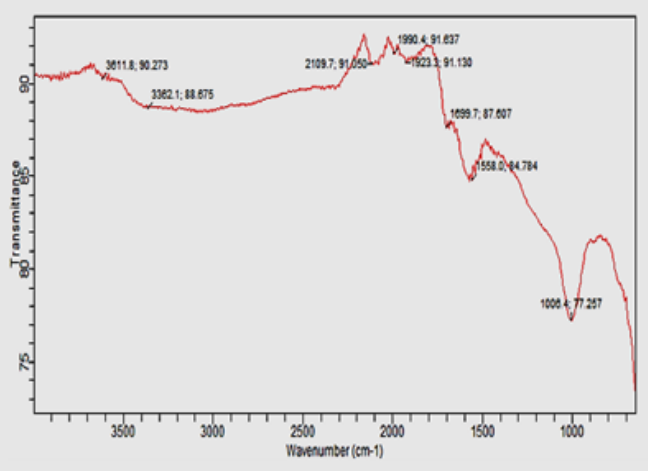

Figure 3: FTIR spectra of adsorbent.

\section{XRD analysis}

The crystalline structure of the adsorbent is given by the XRD spectra shown in Figure 4. The XRD pattern of the crystalline structure of the composite adsorbent shows the characteristic reflections of the homogeneous phase material with slightly uniform peaks with little deviation at low $2 \theta$ angles and other uniform peaks at high $2 \theta$ angles. All the reflections are sharp indicative of a highly crystalline homogeneous phase silicate based material. The uniformity of a series of peaks indexed appearing as symmetric line at high $2 \theta$ angle corresponding to basal spacing indicating the presence of an ordered stacking sequence at atomic scale. The little deviation in the uniformity of peaks with high intensity from other peaks at low $2 \theta$ angle could be attributed to the graphite incorporated in the silicate base material. In order to further confirm the constituent of the adsorbent, other characterization techniques were employed as discussed in the next sections.

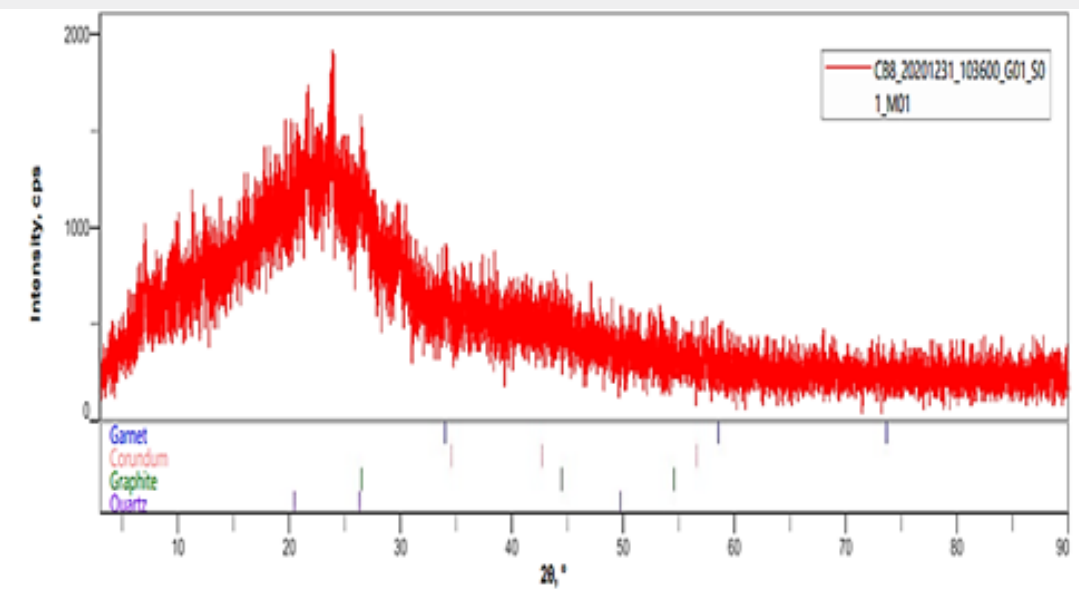

Figure 4: XRD spectra of adsorbent. 


\section{XRF analysis}

Table 4 gives the elemental composition of the adsorbent blend under study. From Table 4, it was found that the blend had a very high concentration of $\mathrm{SiO}_{2}$ of $49.10 \%, \mathrm{Al}_{2} \mathrm{O}_{3}$ of $31.74 \%, \mathrm{~K}_{2} \mathrm{O}$ of $4.55 \%$, $\mathrm{CaO}$ of $3.77 \%, \mathrm{MgO}$ of $3.46 \%$, while others were $3.46 \%$. The elemental composition of the adsorbent as shown in Table 4

Table 3: FTIR analysis. indicates variation in elemental concentrations of metal oxides, which play an important role in the field of catalysis. The transition metals and their compounds are used as catalyst because of their ability to change oxidation state or in the case of the metals, to adsorb other substances on their surface as catalyst. The prepared activated carbon contains various concentrations of metal oxides which may be useful in catalytic processes and adsorption.

\begin{tabular}{|c|c|c|c|c|}
\hline S/No. & Frequency $\left.\mathbf{( c m}^{-1}\right)$ & Appearance & Bonds & Compounds \\
\hline 1 & 2109.7 & Weak absorption band & $\begin{array}{c}\text { C } \equiv \text { C or C } \equiv \text { N stretching vibra- } \\
\text { tion }\end{array}$ & $\begin{array}{c}\text { Alkynes, nitriles } \mathrm{RC} \equiv \mathrm{CH}, \\
\mathrm{RC} \equiv \mathrm{N}\end{array}$ \\
\hline 2 & 1923.3 & Weak absorption band & $\mathrm{Si}-\mathrm{O}, \mathrm{C}=\mathrm{O}$ stretching vibration & $\begin{array}{c}\text { Quartz, carbonate ion or acid } \\
\text { halide }\end{array}$ \\
\hline 3 & 1558 & Fairly strong and little broad absorption band & $\mathrm{C}=\mathrm{C}$ stretching vibration & Alkenes (conjugated) \\
\hline 4 & 1006.4 & Medium, strong and little broad absorption band & $\mathrm{C}=0$ stretching & Acid, esters anhydride \\
\hline
\end{tabular}

Table 4: Elemental composition of CSAC/ZA (wt \%).

\begin{tabular}{|c|c|c|}
\hline Component & Concentration & Error \\
\hline $\mathrm{SiO}_{2}$ & 49.1 & 1.15 \\
\hline $\mathrm{Al}_{2} \mathrm{O}_{3}$ & 31.74 & 1.48 \\
\hline $\mathrm{K}_{2} \mathrm{O}$ & 4.55 & 0.21 \\
\hline $\mathrm{CaO}$ & 3.77 & 0.18 \\
\hline $\mathrm{MgO}$ & 3.46 & 1.89 \\
\hline Others & $<3.46$ & - \\
\hline
\end{tabular}

\section{BET analysis}

The surface area, pore volume and pore size of the adsorbent blend obtained from BET analysis are $428.2 \mathrm{~m}^{2} . \mathrm{g}^{-1}, 0.24 \mathrm{~cm}^{3} \cdot \mathrm{g}^{-1}$ and $2.13 \mathrm{~nm}$, respectively. The BET surface area is the main indicator for the surface properties of activated carbon, as described by $[31,32]$. The high surface area of $428.2 \mathrm{~m}^{2} \cdot \mathrm{g}^{-1}$ of the adsorbent blend calculated by the BET method indicates the possibility of applying the adsorbent for efficient treatment of waste streams laden with

\section{SEM micrograph}

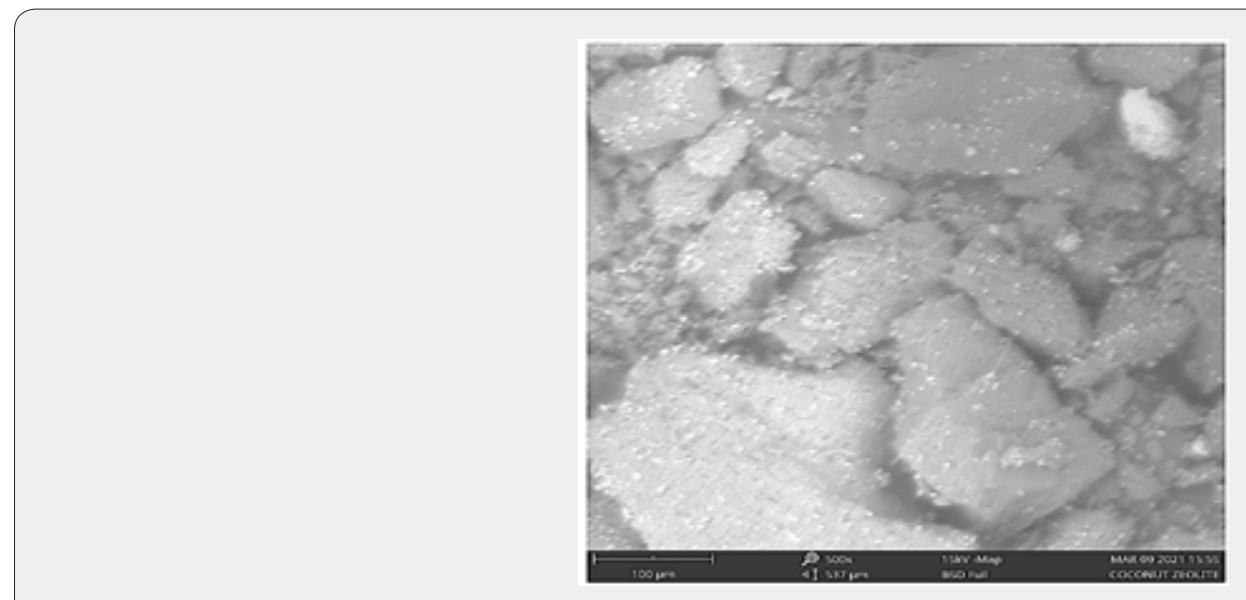

Figure 5: SEM micrograph of CSAC/ZA blend. pollutants. According to the International Union of Pure and Applied Chemistry (IUPAC), the pore development of an activated carbon is classified into three groups which are micropores (size $<2 \mathrm{~nm}$ ), mesopores (2-50nm) and macropores (size > 50nm) $[33,34]$. The pore size of $2.13 \mathrm{~nm}$ of the adsorbent blend falls within the mesoporous pore size distribution. Activation leads to significant formation of micropores and/or mesopores due to the reaction between activating agents and carbon, and results in the enhancement of specific surface area and total pore volume [35]. 
The SEM micrograph of adsorbent is shown in Figure 5. The micrograph of the composite adsorbent shows a highly developed irregular pore structure for the adsorbent. This is evident that there are larger numbers of pores present in the adsorbent which may be due to the presence of zeolite and chemical activation of the coconut shell.

\section{Analysis of adsorption process}

Table 5 gives the experimental design matrix and the predicted and actual values of the amount of TOC and TSS adsorbed by adsorbent blend at a constant $\mathrm{pH}$ of 4.9 .

Table 5: Experimental design matrix and response variables.

\begin{tabular}{|c|c|c|c|c|c|c|c|}
\hline \multirow{3}{*}{ Run } & \multirow{3}{*}{$\begin{array}{c}\text { Actual Factors } \\
\text { (g, ZA) }\end{array}$} & \multicolumn{2}{|c|}{ Adsorbent Dosage Contact } & \multicolumn{4}{|c|}{ Amount Adsorbed (mg/g) } \\
\hline & & \multirow{2}{*}{$\begin{array}{c}\text { Time } \\
\text { (mins) }\end{array}$} & \multirow{2}{*}{$\begin{array}{c}\text { Temperature } \\
\left({ }^{\circ} \mathrm{C}\right)\end{array}$} & \multicolumn{2}{|c|}{ TOC } & \multicolumn{2}{|c|}{ TSS } \\
\hline & & & & Actual & Predicted & Actual & Predicted \\
\hline 1 & 0.21 & 80.11 & 31.68 & 88.5 & 89.32 & 1.51 & 1.52 \\
\hline 2 & 0.5 & 180 & 40 & 96.5 & 99.16 & 0.48 & 0.47 \\
\hline 3 & 0.5 & 180 & 40 & 98.5 & 99.16 & 0.51 & 0.47 \\
\hline 4 & 0.99 & 180 & 40 & 148.87 & 151.65 & 1.76 & 1.74 \\
\hline 5 & 0.5 & 180 & 40 & 103 & 99.16 & 0.52 & 0.47 \\
\hline 6 & 0.5 & 180 & 40 & 102.98 & 99.16 & 0.49 & 0.47 \\
\hline 7 & 0.5 & 348 & 40 & 98.5 & 101.16 & 0.41 & 0.43 \\
\hline 8 & 0.21 & 279.89 & 31.68 & 87.5 & 90.7 & 0.73 & 0.63 \\
\hline 9 & 0.79 & 279.89 & 48.32 & 90.5 & 89.65 & 1.62 & 1.58 \\
\hline 10 & 0.79 & 80.11 & 48.32 & 120.9 & 117.67 & 1.12 & 1.18 \\
\hline 11 & 0.5 & 12 & 40 & 126.19 & 123.57 & 0.81 & 0.84 \\
\hline 12 & 0.79 & 279.89 & 31.68 & 135.5 & 131.78 & 0.71 & 0.76 \\
\hline 13 & 0.21 & 80.11 & 48.32 & 131.5 & 135.19 & 1.11 & 1.03 \\
\hline 14 & 0.01 & 180 & 40 & 134.56 & 131.83 & 1.45 & 1.51 \\
\hline 15 & 0.21 & 279.89 & 48.32 & 130.5 & 127.36 & 0.81 & 0.84 \\
\hline 16 & 0.5 & 180 & 40 & 95.5 & 99.16 & 0.41 & 0.47 \\
\hline 17 & 0.79 & 80.11 & 31.68 & 147.5 & 150.61 & 1.12 & 1.05 \\
\hline 18 & 0.5 & 180 & 26 & 93 & 90.96 & 0.67 & 0.72 \\
\hline 19 & 0.5 & 180 & 40 & 98.5 & 99.16 & 0.44 & 0.47 \\
\hline 20 & 0.5 & 180 & 54 & 92 & 94.09 & 1 & 1 \\
\hline
\end{tabular}

\section{Amount of TOC adsorbed}

As presented in Table 5, the amount of actual TOC adsorbed from the experimental study ranges from 87.50 to $148.87 \mathrm{mg} / \mathrm{g}$ of the adsorbent blend. The maximum amount of TOC adsorbed was achieved at an adsorbent dosage of $0.99 \mathrm{~g}$ zeolite $(0.01 \mathrm{CSAC})$, contact time of $180 \mathrm{~min}$ and temperature of $40^{\circ} \mathrm{C}$, while the minimum amount of TOC adsorbed was achieved at an adsorbent dosage of $0.21 \mathrm{~g}$ zeolite ( $0.79 \mathrm{CSAC}$ ), contact time of $279.89 \mathrm{~min}$ and temperature of 31.68. This indicates that the adsorbent blend with the highest amount of ZA was more effective for TOC adsorption from the studied produced water. To compare the actual TOC adsorbed with the predicted TOC adsorbed (using RSM), a plot was made as depicted in Figure 6.

As shown in Figure 6, it was observed that all points were close to the regression line, which indicates a strong positive linear correlation between the actual and predicted values of the amounts of TOC adsorbed. This means that experimental values of the amount of TOC adsorbed are in reasonable agreement with the predicted values. The close correlation observed in Figure 6 can be further described by the coefficient of determination $\left(\mathrm{R}^{2}\right)$ value, which is a statistical measure that represents the proportion of the variance for a dependent variable that is explained by an independent variable or variables [36]. The adjusted and predicted $\mathrm{R}^{2}$ values obtained from statistical analysis are 0.9638 and 0.8851 respectively, as presented in the model summary statistics in Table 6. Also, from Table 6, it is seen that higher $\mathrm{R}^{2}$ values were observed in the cubic model than other models. For response surface analysis, the cubic model is aliased and hence cannot be used to describe a process. The quadratic model gave better $\mathrm{R}^{2}$ values than the $2 \mathrm{FI}$ (two factor interaction) and linear sources of the model, making the quadratic model the best model which describes the TOC adsorption from the studied produced water. 


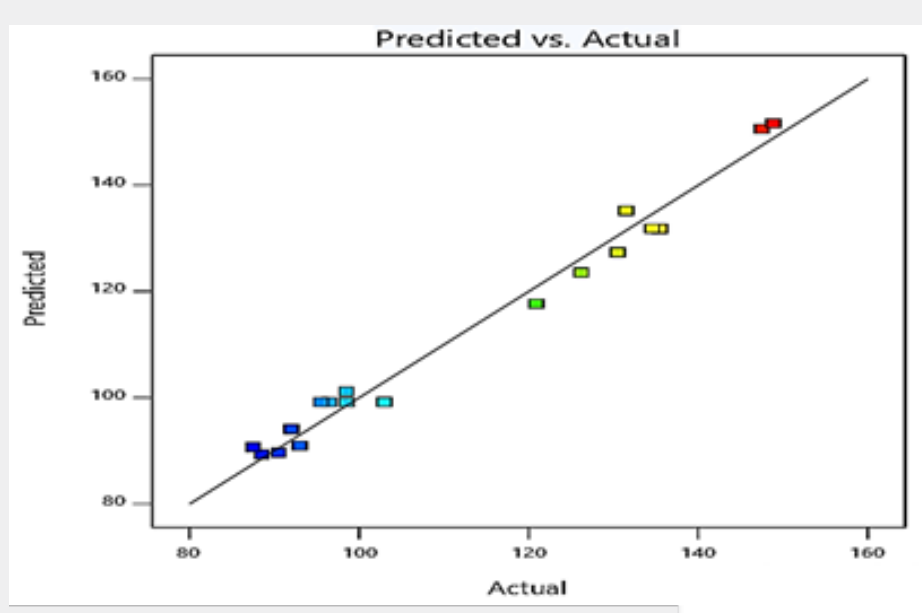

Figure 6: Predicted vs actual plot of TOC adsorption.

Table 6: Model summary statistics.

\begin{tabular}{|c|c|c|c|c|c|c|}
\hline Source & Standard Deviation & $\mathbf{R}^{2}$ & Adjusted $\mathrm{R}^{2}$ & Predicted $\mathbf{R}^{2}$ & PRESS & \\
\hline Linear & 21.1695 & 0.1322 & -0.0306 & -0.5241 & 12592.84 & \\
\hline $2 \mathrm{FI}$ & 17.1404 & 0.5377 & 0.3244 & 0.0071 & 8203.371 & \\
\hline Quadratic & 3.9664 & 0.981 & 0.9638 & 0.8851 & 949.6169 & Suggested \\
\hline Cubic & 2.9065 & 0.9939 & 0.9806 & 0.9911 & 73.9285 & Aliased \\
\hline
\end{tabular}

To further analyse the amount of TOC adsorbed statistically, ANOVA was carried out on the data obtained. Table 7 gives the ANOVA of the amount of TOC adsorbed from produced water by the adsorbent blend. P-values less than 0.05 indicates model terms/factors that are significant i.e., change in the factor leads to a corresponding change in the amount of TOC adsorbed at a significant level of $5 \%$.

Table 7: ANOVA of TOC adsorption.

\begin{tabular}{|c|c|c|c|c|c|}
\hline Source & Sum of Squares & Df & Mean Sum of Squares & F-value & P-value \\
\hline Model & 8104.94 & 9 & 900.549 & 57.2432 & $0.0000^{*}$ \\
\hline A & 474.11 & 1 & 474.11 & 30.1367 & $0.0003^{*}$ \\
\hline B & 605.947 & 1 & 605.947 & 38.5169 & $0.0001^{*}$ \\
\hline $\mathrm{C}$ & 11.8441 & 1 & 11.8441 & 0.7529 & 0.4059 \\
\hline $\mathrm{AB}$ & 204.02 & 1 & 204.02 & 12.9685 & $0.0048^{*}$ \\
\hline $\mathrm{AC}$ & 3104.72 & 1 & 3104.72 & 197.351 & $0.0000^{*}$ \\
\hline $\mathrm{BC}$ & 42.32 & 1 & 42.32 & 2.6901 & 0.132 \\
\hline $\mathrm{A}^{2}$ & 3265.18 & 1 & 3265.18 & 207.55 & $0.0000^{*}$ \\
\hline $\mathrm{B}^{2}$ & 314.079 & 1 & 314.079 & 19.9644 & $0.0012 *$ \\
\hline$C^{2}$ & 79.4419 & 1 & 79.4419 & 5.0497 & $0.0484^{*}$ \\
\hline Residual & 157.32 & 10 & 15.732 & & \\
\hline Lack of fit & 106.64 & 5 & 21.3279 & 2.1042 & 0.2168 \\
\hline Pure error & 50.6803 & 5 & 10.1361 & & \\
\hline Cor. Total & 8262.26 & 19 & & & \\
\hline
\end{tabular}

*=significant. 
As shown in Table 7, a high model f-value of 57.2432 and a very low p-value of 0.0000 obtained indicates that the model term is highly significant. Among the main factors, adsorbent dosage and contact time with low p-values $<0.05$ (0.0003 and 0.0001 respectively) had a significant effect on the amount of TOC adsorbed from produced water using the adsorbent blends, while the effect of temperature ( $p$-value of $0.4059>0.05$ ) did not have any significant effect on the amount of TOC adsorbed. Among the interaction variables, $\mathrm{AB}$ and $\mathrm{AC}$ had significant effects on the amount of TOC adsorbed while BC was insignificant. All quadratic factors $\left(\mathrm{A}^{2}, \mathrm{~B}^{2}\right.$ and $\left.\mathrm{C}^{2}\right)$ had a significant effect on the amount of TOC adsorbed with p-values less than 0.05 , however, the $C^{2}$ was only slightly significant. It is important to note that the p-value of the lack of fit was found to be insignificant with a high value of 0.2168 , which is desirable for an appropriate model fit.

Furthermore, the empirical model showing the relationship between the variables considered in coded form is given in Eq. 4 .

TOC Value $=99.16+5.89 A-6.66 B+0.93 C-5.05 A B-19.70 A C-$

$$
2.30 B C+15.05 A^{2}+4.67 B^{2}-2.35 C^{2}
$$

According to literature $[37,38]$, when an independent variable has a positive sign in a regression equation, it means that an increase in the variable will cause an increase in the response while a negative sign will result in a decrease in the response. Among the main factors, adsorbent dosage and temperature had positive effects on the amount of TOC adsorbed while contact time had a negative effect. All interaction factors had negative effects on the amount of TOC adsorbed. The quadratic factors $\left(\mathrm{A}^{2}\right.$ and $\left.\mathrm{B}^{2}\right)$ had positive effects on the amount of TOC adsorbed while $\mathrm{C}^{2}$ had negative effect. The model can be further described using the fit statistic given in Table 8.

Table 8: Fit statistics of model.

\begin{tabular}{|c|c|}
\hline Parameter & Value \\
\hline Standard deviation $(\mathrm{mg} / \mathrm{g})$ & 3.9664 \\
\hline Mean $(\mathrm{mg} / \mathrm{g})$ & 111.025 \\
\hline C.V (\%) & 3.5725 \\
\hline $\mathrm{R}^{2}$ & 0.981 \\
\hline Adjusted $\mathrm{R}^{2}$ & 0.9638 \\
\hline${\text { Predicted } \mathrm{R}^{2}}^{2}$ & 0.8851 \\
\hline Adequate precision & 22.2213 \\
\hline
\end{tabular}

The coefficient of variation (C.V) of $3.5725 \%$ is within the acceptable range, since $\mathrm{CV}$ is a measure of expressing standard deviation as a percentage of the mean, the small values of $\mathrm{CV}$ gives better reproducibility. In general, a high $\mathrm{CV}$ indicates that variation in the mean value is high and does not satisfactorily develop an adequate response model $[39,40]$. The coefficient of regression $\mathrm{R}^{2}$ was used to validate the fitness of the model equation. Table 8 gives an $\mathrm{R}^{2}$ of a high value of 0.9810 , which shows that about
$98 \%$ of the variability in the amount of TOC adsorbed by the variables considered can be explained by the model. There is also a reasonable agreement between the adjusted $R^{2}(0.9638)$ and the predicted $R^{2}(0.8851)$ values, which shows that the model (in Eq. 4) reasonably predicted the TOC adsorption process using a quadratic polynomial. Adequate precision measures the signal to noise ratio, and a ratio greater than 4 is desirable. The ratio of 22.2213 indicates an adequate signal [37]. This indicates that the model can be used to navigate the design space. Based on these findings, the effect of variables interaction on the amount of TOC adsorbed can be further analysed, as discussed in the next section.

\section{Effects of the interaction of variables on amount of TOC adsorbed}

The effects of the interaction of variables on the amount of TOC adsorbed from produced water by the adsorbent blend are shown in Figure 7a-7c. Figure 7a shows the effect of the interaction of adsorbent dosage and contact time (AB) on the amount of TOC adsorbed by the composite adsorbent. As displayed in the plot, an increase in the adsorbent dosage leads to an increase in the amount of TOC adsorbed by the composite adsorbent, while, increase in the contact time lead to decrease in the amount of TOC adsorbed. Contact time had a more dominant effect than the adsorbent dosage. The concurrent increase in the adsorbent dosage and contact time leads to a decrease in the amount of TOC adsorbed by the adsorbent. Figure $7 \mathrm{~b}$ depicts the effect of the interaction of adsorbent dosage and temperature (AC) on the amount of TOC adsorbed by the composite adsorbent. From the plot, it is observed that at constant temperature, increase in adsorbent dosage leads to increase in the amount of TOC adsorbed by the adsorbent while at constant adsorbent dosage, increase in temperature also lead to increase in the amount of TOC adsorbed. Adsorbent dosage had a more dominant effect than temperature. The concurrent increase in adsorbent dosage and temperature lead to a decrease in the amount of TOC adsorbed by the adsorbent. Figure 7c shows the effect of the interaction of contact time and temperature on the amount of TOC adsorbed by the composite adsorbent. From the plot, at constant temperature, increase in contact time lead to decrease in the amount of TOC adsorbed while at constant contact time, increase in temperature lead to increase in the amount of TOC adsorbed. The effect of contact time is more dominant than that of temperature. The concurrent increase in the contact time and temperature lead to a decrease in the amount of TOC adsorbed by the adsorbent blend.

\section{Optimization of TOC adsorption}

The desirability ramp showing the optimal conditions of variables is shown in Figure 8. A numerical optimization technique using desirability functions was employed to optimise the response (amount of TOC adsorbed) from produced water by the adsorbent blend. The objective of the optimization was to find the best settings that maximise the amount of TOC adsorbed in the process using a desirability value, where $0 \leq d \leq 1$. The value of 
$d$ increases as the desirability of the corresponding response increases. The variable settings with maximum desirability are considered to be the optimal parameter conditions. The achieved maximum desirability of 1.000 means that it is possible to reach the maximum amount of TOC adsorbed target. The maximum amount of TOC adsorbed in the adsorption process predicted was $150.020 \mathrm{mg} / \mathrm{g}$. This was achieved using an adsorbent dosage of $0.79 \mathrm{~g}$ ZA $(0.29 \mathrm{~g} \mathrm{CSAC})$, contact time of $80.52 \mathrm{mins}$, and a temperature of $32.01^{\circ} \mathrm{C}$. Figure 8 shows the numerical optimization ramp of the TOC adsorption process which gives credence to the obtained result.
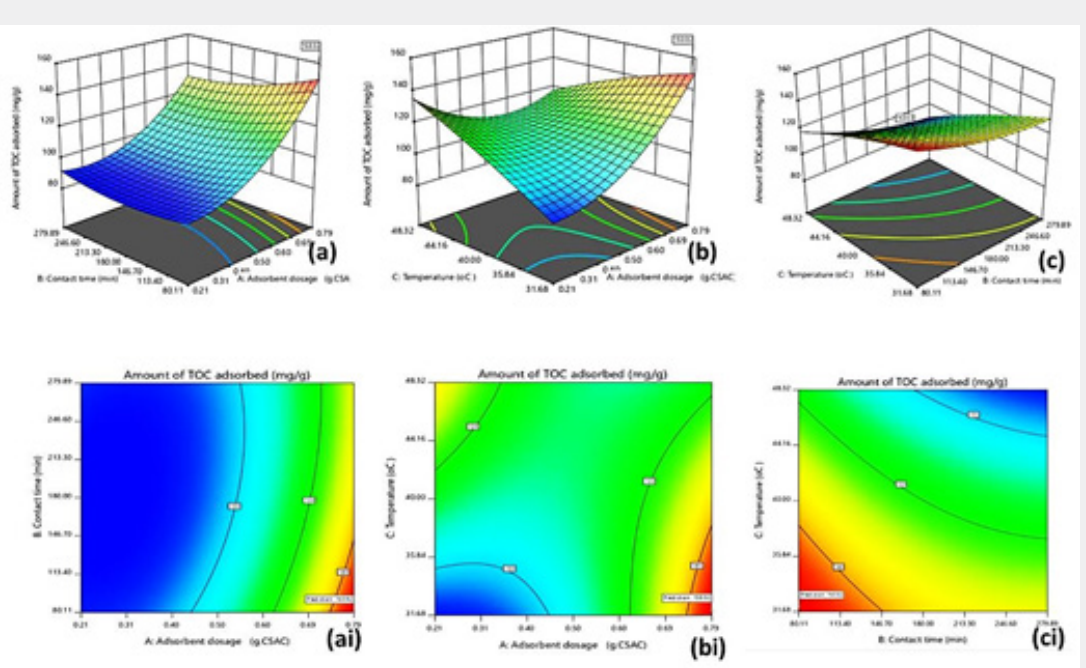

Figure 7: Effect of interaction of variables on the amount of TOC adsorbed (a) interaction of adsorbent dosage and contact time, (b) interaction of adsorbent dosage and temperature and (c) interaction of contact time and temperature.
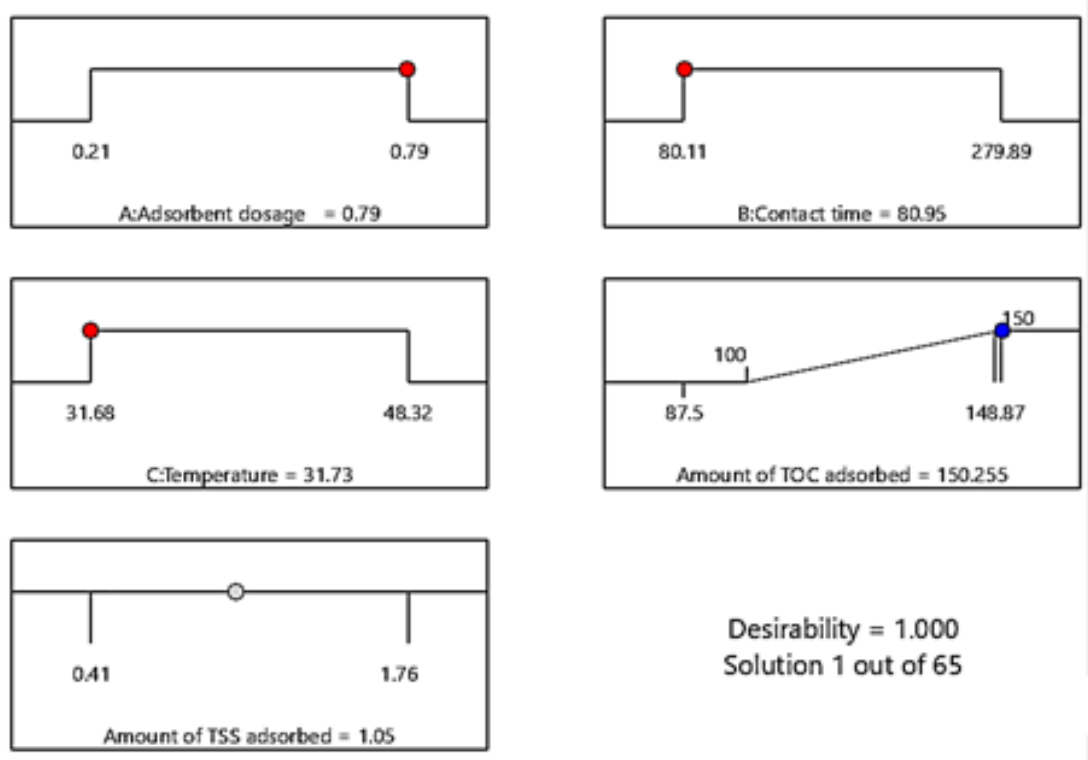

Desirability $=1.000$

Solution 1 out of 65

Figure 8: Desirability ramp of TOC adsorption.

\section{Amount of TSS adsorbed}

As shown in Table 5, the amount of TSS adsorbed ranged from 0.41 to $1.76 \mathrm{mg} / \mathrm{g}$ of the adsorbent blend. The maximum amount of TSS adsorbed was achieved at an adsorbent dosage of $0.99 \mathrm{~g}$. ZA ( $0.01 \mathrm{CSAC})$, contact time of $180 \mathrm{mins}$ and temperature of $40^{\circ} \mathrm{C}$, while the minimum amount of TSS adsorbed was achieved at an adsorbent dosage of $0.50 \mathrm{~g} . \mathrm{ZA}(0.50 \mathrm{CSAC})$, contact time of $180 \mathrm{mins}$ and temperature of $40^{\circ} \mathrm{C}$. This indicates that the adsorbent blend with the highest amount of ZA was more effective for TSS adsorption from the studied produced water. To compare the actual TSS adsorbed with the predicted TSS adsorbed (using RSM), a plot was made as depicted in Figure 9. 


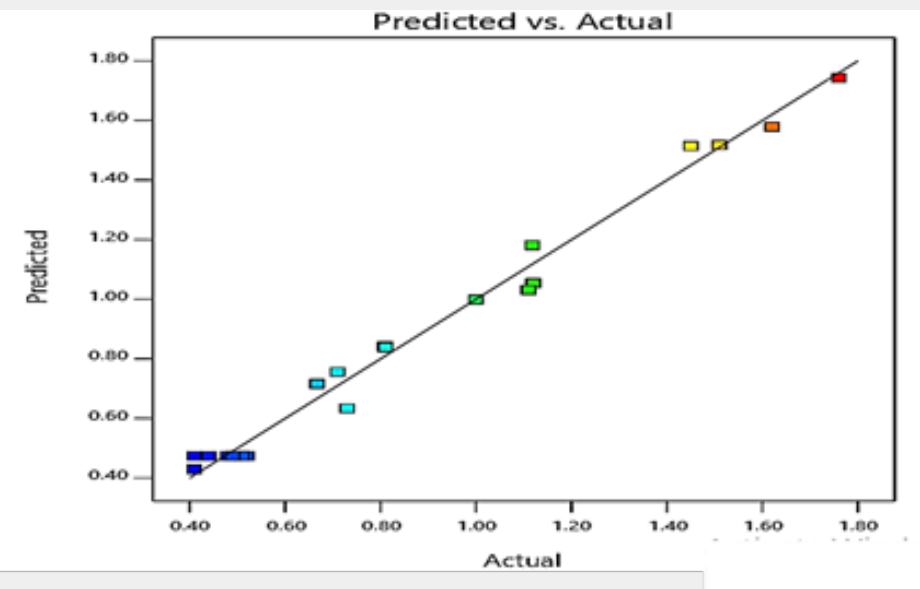

Figure 9: Predicted vs. actual plot of TSS adsorption.

All points were close to the regression line, which indicates a strong positive linear correlation between the actual and predicted values of the amounts of TSS adsorbed. This implies that the experimental values of the amount of TSS adsorbed are in reasonable agreement with the predicted values, thereby giving credence to the actual/experimental results. The close correlation observed in Figure 9 can be further described by the closeness of the adjusted and predicted $\mathrm{R}^{2}$ values of 0.9755 and 0.9072 respectively in the model summary statistics presented in Table 9. Also from Table 9, higher $\mathrm{R}^{2}$ values were observed in the cubic model than other models. For response surface analysis, the cubic model is aliased and hence cannot be used to describe a process. The quadratic model gave better $\mathrm{R}^{2}$ values than the 2FI (twofactor interaction) and linear sources of the model, making the quadratic model the best model that describes the TSS adsorption from the studied produced water.

Table 9: Model summary statistics.

\begin{tabular}{|c|c|c|c|c|c|c|}
\hline Source & Standard Deviation & $\mathbf{R}^{2}$ & Adjusted $\mathbf{R}^{2}$ & Predicted R $^{2}$ & PRESS & \\
\hline Linear & 0.4461 & 0.102 & -0.0664 & -0.4436 & 5.1183 & 6.2269 \\
\hline 2FI & 0.4456 & 0.2719 & -0.0641 & -0.7562 & 0.3289 & Suggested \\
\hline Quadratic & 0.0676 & 0.9871 & 0.9755 & 0.9072 & 1.2551 & Aliased \\
\hline Cubic & 0.0493 & 0.9959 & 0.987 & 0.646 & & \\
\hline
\end{tabular}

To further analyse the amount of TSS adsorbed statistically, ANOVA was carried out on the data obtained. Table 10 gives the ANOVA of the amount of TSS adsorbed from produced water by the adsorbent blend at a significant level of $5 \%$.

As presented in Table 10, model F-value of 85 and a very small p-value $<0.0001$ showed that the model term is highly significant. All factors (main, interaction, and quadratic factors) with p-values $<0.05$ were found to have significant effects on the amount of TSS adsorbed from produced water by the adsorbent blend. The p-value of the lack of fit was found to be insignificant with a high value of 0.0734 , which is desirable for an appropriate model fit.

Furthermore, the empirical model showing the relationship between the variables considered in coded form is given in Eq. 5 .

Amount of TSS absorbed $\left(\frac{m g}{g}\right)=0.4736+0.0681 A-0.1216 B+0.0841 C+$

$0.1465 A B+0.1535 A C+0.1740 B C+0.4084 A^{2}+0.0566 B^{2}+0.1356 C^{2}$

(6)
From Eq. 5, it can be observed that all factors except contact time have positive effects on the amount of TSS adsorbed from produced water by the adsorbent blend of coconut shell and zeolite. Contact time had the highest significant effect on the amount of TSS adsorbed while adsorbent dosage had the least effect among the main factors. The fitness of the model (Eq. 5) can be further described using the fit statistics shown in Table 11.

From Table 11, the C.V was found to be $7.6538 \%$, which is within the acceptable range. The coefficient of regression $\mathrm{R}^{2}$ for validating the fitness of the model gave a high value of 0.9871 , which shows that about $99 \%$ of the variability in the amount of TSS adsorbed by the variables can be explained by the model given in Eq. 5. Furthermore, a reasonable agreement between the adjusted $\mathrm{R}^{2}$ and the predicted $\mathrm{R}^{2}$ values of 0.9755 and 0.9072 respectively (the difference is $<0.2$ ) was observed, which shows that the model (in Eq. 5) reasonably predicted the TSS adsorption process using a quadratic polynomial. Adequate precision gave a ratio of 27.4719 
which indicates an adequate signal, thereby giving credence for the model to be used to navigate the design space. Based on these findings, the effect of variables interaction on the amount of TOC adsorbed can be further analysed, as discussed in the next section.

Table 10: ANOVA of TSS adsorption.

\begin{tabular}{|c|c|c|c|c|c|}
\hline Source & Sum of Squares & df & Mean Square & F-value & p-value \\
\hline Model & 3.5 & 9 & 0.3889 & 85 & $<0.0001^{*}$ \\
\hline A & 0.0632 & 1 & 0.0632 & 13.82 & $0.0040^{*}$ \\
\hline $\mathrm{B}$ & 0.2019 & 1 & 0.2019 & 44.14 & $<0.0001^{*}$ \\
\hline $\mathrm{C}$ & 0.0965 & 1 & 0.0965 & 21.09 & $0.0010^{*}$ \\
\hline $\mathrm{AB}$ & 0.1717 & 1 & 0.1717 & 37.53 & $0.0001^{*}$ \\
\hline $\mathrm{AC}$ & 0.1885 & 1 & 0.1885 & 41.2 & $<0.0001^{*}$ \\
\hline $\mathrm{BC}$ & 0.2422 & 1 & 0.2422 & 52.94 & $<0.0001^{*}$ \\
\hline$A^{2}$ & 2.4 & 1 & 2.4 & 525.31 & $<0.0001^{*}$ \\
\hline $\mathrm{B}^{2}$ & 0.0462 & 1 & 0.0462 & 10.09 & $0.0099^{*}$ \\
\hline $\mathrm{C}^{2}$ & 0.265 & 1 & 0.265 & 57.93 & $<0.0001^{*}$ \\
\hline Residual & 0.0458 & 10 & 0.0046 & & \\
\hline Lack of Fit & 0.0368 & 5 & 0.0074 & 4.11 & 0.0734 \\
\hline Pure Error & 0.009 & 5 & 0.0018 & & \\
\hline Cor. Total & 3.55 & 19 & & & \\
\hline
\end{tabular}

*=significant.

Table 11: Fit statistics of model.

\begin{tabular}{|c|c|}
\hline Parameter & Value \\
\hline Standard deviation $(\mathrm{mg} / \mathrm{g})$ & 0.0676 \\
\hline Mean $(\mathrm{mg} / \mathrm{g})$ & 0.8838 \\
\hline C.V $(\%)$ & 7.6538 \\
\hline $\mathrm{R}^{2}$ & 0.9871 \\
\hline Adjusted $\mathrm{R}^{2}$ & 0.9755 \\
\hline Predicted $\mathrm{R}^{2}$ & 0.9072 \\
\hline Adequate precision & 27.4719 \\
\hline
\end{tabular}

Effects of the interaction of variables on amount of TSS adsorbed

The effects of the interaction of variables on the amount of TSS adsorbed from produced water by the adsorbent blend are shown in Figure 10a-10c. Figure 10a shows the effect of the interaction of adsorbent dosage and contact time on the amount of TSS adsorbed at a constant temperature. At constant adsorbent dosage, an increase in contact time led to a decrease in the amount of TSS adsorbed while an increase in adsorbent dosage at constant contact time leads to an increase in the amount of TSS adsorbed. The simultaneous increase in adsorbent dosage and contact time leads to an increase in the amount of TSS adsorbed. Figure $10 \mathrm{~b}$ shows the effect of the interaction of adsorbent dosage and temperature on the amount of TSS adsorbed at constant contact time. From the plot, at constant adsorbent dosage, increase in temperature lead to increase in the amount of TSS adsorbed while at constant temperature increase in adsorbent dosage lead to increase in the amount of TSS adsorbed. The simultaneous increase in adsorbent dosage and temperature lead to increase in the amount of TSS adsorbed. Figure 10c shows the interaction effect of contact time and temperature on the amount of TSS adsorbed at constant sorbent dosage. From the plot, at constant contact time, increase in temperature lead to increase in the amount of TSS adsorbed while at constant temperature increase in contact time lead to decrease in the amount of TSS adsorbed.

\section{Optimization of TSS adsorption}

Figure 11 shows the desirability ramp of the optimization TSS adsorption by the adsorbent blend. The achieved maximum desirability of 0.83 means that it is possible to a reach maximum of $83 \%$ amount of the TSS adsorbed target. The maximum amount of TSS adsorbed in the adsorption process predicted was $1.579 \mathrm{mg} / \mathrm{g}$. This was achieved using an adsorbent dosage of 0.79 ZA (0.21g CSAC), contact time of 279.89 mins, and a temperature of $48.32^{\circ} \mathrm{C}[41,42]$.

\section{Conclusion}

The following conclusions were drawn from the adsorptive treatment of TOC and TSS in oilfield- produced water using an adsorbent blend prepared from coconut shell activated carbon and zeolite.

a) The adsorbent blend of coconut shell activated carbon and zeolite contain higher amounts of the metal oxides in the following order; $\mathrm{SiO}_{2}>\mathrm{Al}_{2} \mathrm{O}_{3}>\mathrm{K}_{2} \mathrm{O}>\mathrm{CaO}>\mathrm{MgO}$. The BET surface 
area, pore volume and pore size were found to be $428.2 \mathrm{~m}^{2} \cdot \mathrm{g}^{-1}$, $0.24 \mathrm{~cm}^{3} \cdot \mathrm{g}^{-1}$ and $2.13 \mathrm{~nm}$ respectively. The surface morphology of the adsorbent blend as revealed by the SEM micrograph showed a highly developed irregular pore structure which is due to chemical activation and/or presence of zeolite in the adsorbent. The functional group showed the presence of alkyne, quartz, alkene, and acid esters, while the XRD revealed a high crystalline structure of the adsorbent.

b) The point of zero charge of the adsorbent blend was found to be 4.9 which is acidic.

c) The physico-chemical properties of the produced water which showed a TOC and TSS values of $3590 \mathrm{mg}^{-l^{-1}}$ and $52.34 \mathrm{mg} . \mathrm{l}^{-1}$ respectively, revealed that the water was contaminated according to the DPR permissible limits.

d) The actual maximum amount of TOC adsorbed in the adsorption process was $148.87 \mathrm{mg} \cdot \mathrm{g}^{-1}$. This was achieved at an adsorbent dosage of $0.99 \mathrm{~g}$. zeolite $(0.01 \mathrm{CSAC})$, contact time of $180 \mathrm{mins}$ and temperature of $40^{\circ} \mathrm{C}$, while the actual maximum amount of TSS adsorbed in the adsorption process was $1.76 \mathrm{mg} . \mathrm{g}$ 1. This was achieved at an adsorbent dosage of 0.99 g.ZA $(0.01$ CSAC), contact time of $180 \mathrm{mins}$ and temperature of 40 . The actual amounts of TOC and TSS adsorbed via experiment were relatively close to the predicted values, thereby giving credence to the adsorption study.

e) Based on the statistical analysis using the response surface methodology, a quadratic model was developed.
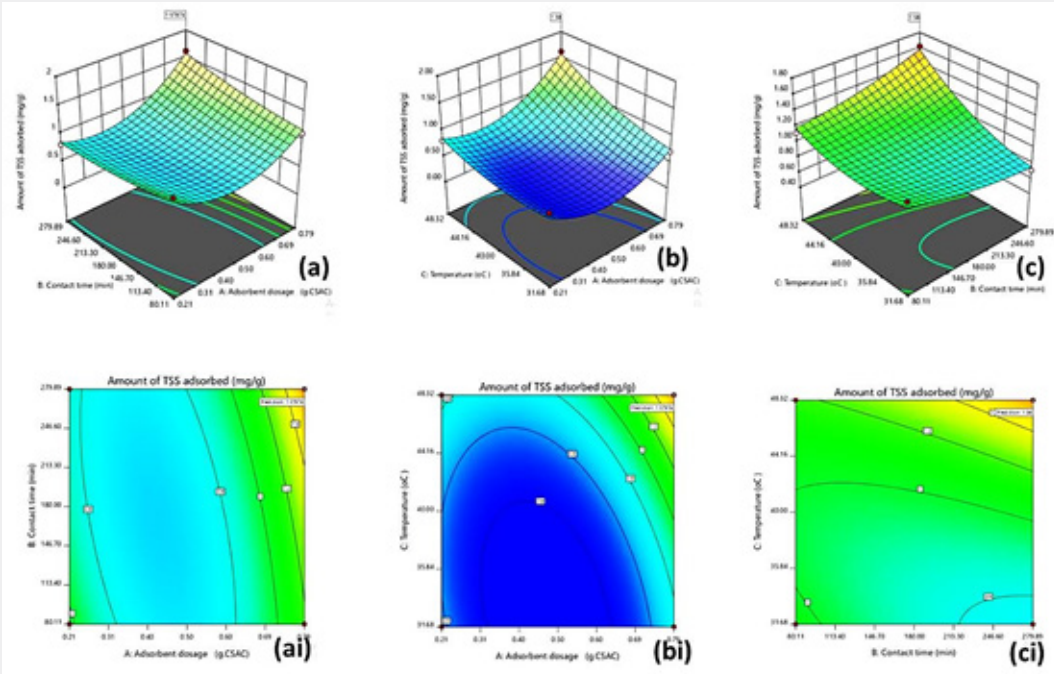

Figure 10: Effect of interaction of variables on the amount of TSS adsorbed (a) interaction of adsorbent dosage and contact time, (b) interaction of adsorbent dosage and temperature and (c) interaction of contact time and temperature.
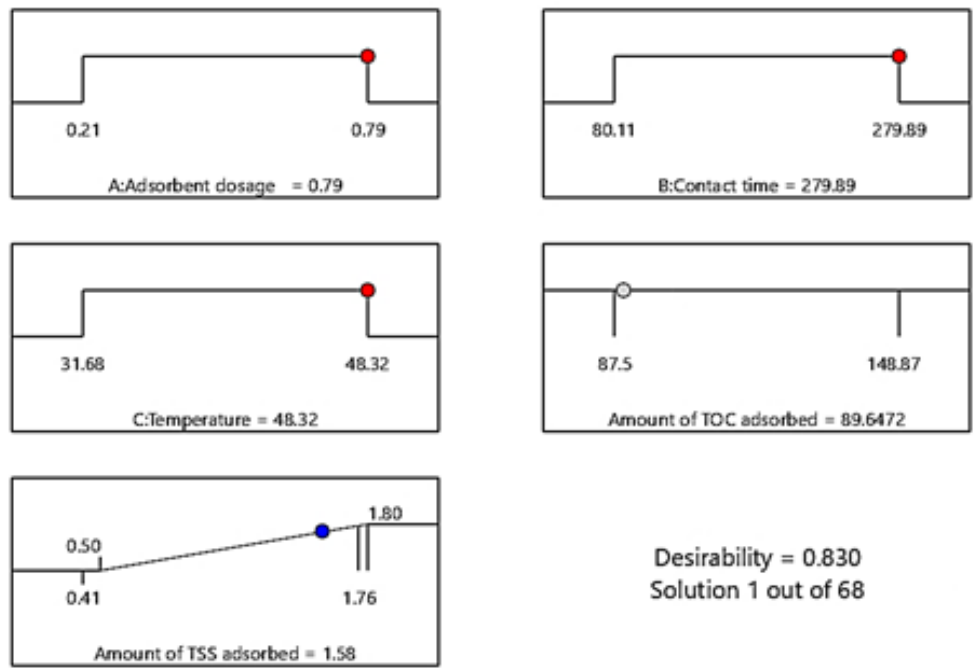

Desirability $=0.830$

Solution 1 out of 68

Figure 11: Desirability ramp of TSS adsorption. 


\section{Acknowledgment}

\section{This work had no funding}

The authors are grateful to late Dr. Martin J. Okonkwo for his technical input and support in the preparation of this work.

\section{Data availability}

The raw/processed data required to reproduce these findings cannot be shared at this time due to technical or time limitations.

\section{Declaration of Interest}

This manuscript has not been published previously and is not under consideration for publication elsewhere. We have no conflict of interest in the submission of this manuscript, and the manuscript is approved by all authors for publication. No funding was available for this work. We greatly appreciate your time to review our manuscript and we are looking forward to hearing from you.

\section{Authors Contribution}

Camillus U. Okonkwo: Conceptualization, methodology, formal analysis, investigation, data curation, writing-original draft, and visualization.

Bright 0. Okonkwo: Data curation, writing-original draft, Validation, editing, visualization,

Sylvester Uwadiae: Methodology, validation, writing-review and editing, supervision, project and administration.

Chigoziri Njoku: writing-review and editing.

\section{References}

1. Kanu I, Achi O (2011) Industrial effluents and their impact on water quality of receiving rivers in Nigeria. Journal of Applied Technology in Environmental Sanitation 1: 75-86.

2. SO Fakayode (2005) Impact assessment of industrial effluent on water quality of the receiving Alero River in Ibadan, Nigeria. Ajeamragee 10: $1-13$.

3. AY Sangodoyin (1995) Characteristics of control of industrial effluents- generated pollution. Journal of Environmental Management and Health 6(4): 15-18.

4. ME Ikpi, BO Okonkwo (2017) Electrochemical investigation on the corrosion of API 5L X52 carbon steel in simulated soil solutions. Journal of Material Environmental Science 8(11): 3809-3816.

5. R Bradley (2014) Method of recovering gas from shale reservoirs and purifying resulting produced water to allow the produced water to be used as drilling. US Patent 8: 734: 650.

6. MT Stephenson (1994) A survey of produced water studies. Environmental Science Research Book Series (ESRH) 46: 1-11.

7. PR Krause (1995) Spatial and temporal variability in receiving water toxicity near an oil effluent discharge site. Archives of Environmental Contamination and Toxicology 29: 523-529.

8. A FakhruI Razi, Pendashteh A, Abdullah LC, Biak DRA, Madaeni SS, et al. (2009) Review of technologies for oil and gas produced water treatment. Journal of hazardous materials $170(2-3)$ : 530-551.
9. Al- Malack MH (2013) Treatment of petroleum refinery wastewater using crossflow and immersed membrane process. Desalination and Water Treatment 51(37-39): 37-39.

10. PJ Ray, FR Engelhardt (1992) Produced Water, Technological/ Environmental Science Research, Plenum press, New York, pp. 35-41.

11. T Sirivedhin, D Liese (2004) Organic matrix in produced water from the Osage- Skiatook Petroleum Environmental Research site, Osage county, Oklahoma. Chemosphere 57(6): 463-469.

12. CO Igwe, A Al Saadi, SE Ngene (2013) Optimal options for treatment of produced water in platforms. Journal of Pollution Effects and Control 1: 102-103.

13. L Hushu (2013) Produced water quality characterization wattenberg field. Department of Civil and Environmental Engineering Colorado State University Fort Collins, Colorado, pp. 40-60.

14. D Mohan, KP Singh, S Gurdeep, K Kundan (2002) Removal of dyes from wastewater using flyash a low cost Adsorbent. Industrial and Engineering Chemistry Research 41(15): 3688-3695.

15. R Malik, L Suman, S Sushila (2015) Removal of heavy metals from waste water by the use of modified aloe vera leaf powder. International Journal of Basic and Applied Chemistry Science 5(2): 6-17.

16. MGA Vieira, N AF de Almeida, MG Silva, CC Nobrega, AA Melo Filho (2012) Characterization and use of natural and calcined rice husks for biosorption of heavy metal ions from aqueous effluents. Brazilian Journal of Chemical Engineering 29(3): 619-634.

17. F Nur-Azreen, SI Ahmmed, NI Kamariah (2014) Removal of heavy metals from simulated waste water using physically and chemically modified palm shell activated carbon. Journal of Applied Sciences 14(12): 1294-1295

18.S Babel, TA Kurniawan (2003) Low-cost adsorbents for heavy metals uptake from contaminated water. Journal of Hazard Material 97(1-3): 219-243.

19. CK Rojas Mayorga, DI Mendoza Castillo, A Bonilla Petriciolet (2016) Tailoring the adsorption behavior of bone char for heavy metal removal from aqueous solution. Adsorption Science and Technology 34(6): 368-378.

20. (2005) ASTM D888-18, Standard test methods for dissolved oxygen in water, ASTM International, West Conshohocken, PA.

21. NAS Mohammed, RA Abu Zurayk, I Hamadneh, AH Al Dujaili (2018) Phenol adsorption on biochar prepared from the pine fruit shells: Equilibrium, kinetic and thermodynamics studies. Journal of Environmental Management 226: 377-385.

22. FT Ademiluyi, EO David West (2012) Effect of chemical activation on the adsorption of heavy metals using activated carbons from waste materials. International Scholarly Research Notices 2012(674209): $1-5$.

23. SL Pandharipand, GA Borkar (2016) Synthesis of chitin from crab shell and its uses in preparation of nanostructured film. International Journal of Science, Engineering and Technology Research (IJSETR) 5: 14841488.

24. N Foil, I Villaescusa (2009) Determination of sorbent point zero charge: usefulness in sorption studies. Environmental Chemistry Letters 7: 79-84.

25. Argun ME, Ozudemis C, Kanatas M, Dursun S (2007) Heavy metal adsorption by modified Oak Sawdust: Thermodynamics and kinetics hazardous materials. Journal Colloid Interface Science 141(1): 77-87.

26. 0 Okieimen, FE Okieimen (2001) Enhanced metals adsorption by ground nut (arachislypugea) husk modified with thioglycolic acid. Bulletin Pure and Applied Science 20: 13-20. 
27. C Chen, J Dynes, J Wang, DL Sparks (2014) Properties of Fe-organic matter associations via coprecipitate versus adsorption. Environmental Science and Technology 48(23): 13751-13759.

28. J Neff, K Lee, EM DeBlois (2011) Produced water: Overview of composition, fates, and effects. Produced Water, Springer, New York, NY, USA, pp. 3-54.

29. Department of petroleum resources (DPR) (1998) Environmental guidelines and standards for the petroleum industry in Nigeria (EGASPIN), pp. 3-5.

30. Water Salinity Quality Standards (2013) Water quality standards.

31. BM Babic, SK Milonjic, MJ Polovina, BV Kaludierovic (1999) Point charge and intrinsic equilibrium constants of activated carbon cloth. Carbon 37(3): 477-481.

32. MAP Cechinel, SMAG Ulson de Souza, AA Ulson de Souza (2013) Study of lead (II) adsorption onto activated carbon originating from cow bone. Journal of Cleaner Production 65: 342-349.

33. TC Chandra, MM Mirna, J Sunarso, Y Sudaryanto, S Ismadji (2009) Activated carbon from durian shell: Preparation and Characterization. Journal of the Taiwan Institute of Chemical Engineers 40(4): 457-462.

34. D Kalderis, P Paraskeva, E Diamadopoulos (2009) Production of activated carbon from agricultural by-products. Journal of Chemical Technology and Biotechnology: International Research in Process Environmental and Clean Technology 83: 581-592.

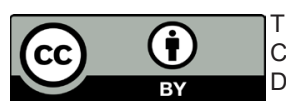

This work is licensed under Creative Commons Attribution 4.0 License

DOI: 10.19080/IJESNR.2022.29.556275
35. AG Pandolfo, AF Hollenkamp (2005) Carbon properties and their role in super capacitors. Journal of Power Sources 157(1): 11-27.

36. MN Mohd Iqbaldin, I Khudzir, MI Mohd Azlan, AG Zaidi, B Surani, et al. (2013) Properties of coconut shell activated carbon. Journal of Tropical Forest Science 25(4): 497-503.

37. HM Lee, HG Kim, SJ Kang, SJ Park, KH An, et al. (2014) Effects of pore structures on electrochemical behaviors of polyacrylonitrile (PAN)based activated carbon nanofibers. Journal of Industrial Engineering Chemistry 21: 736-740.

38. F Ying, BY Gao, YF Zhang, XY Zhang, N Shi (2011) Organic modifier of poly-silicic-ferric coagulant: Characterization, treatment of dyeing wastewater and floc change during coagulation. Desalination 277: 6773.

39. VL Russell (2009) Response surface methods in R, using RSM, J. Stat Ease Software, Mineapolis, USA.

40. O Ocholi, M Menkiti, M Auta, I Ezemagu (2018) Optimization of the operating parameters for the extractive synthesis of biolubricant from sesame seed oil via response surface methodology. Egyptian Journal of Petroleum 27(3): 265-275.

41.WW Daniel (1991) Biostatistics: A Foundation for Analysis in the Health Sciences $\left(5^{\text {th }}\right.$ edn). New York, Wiley, USA.

42. C Liyana Pathirana, F Shahidi (2005) Optimization of extraction of phenolic compounds from wheat using response surface methodology. Food Chemistry 93(1): 47-56.

\begin{tabular}{l} 
Your next submission with Juniper Publishers \\
will reach you the below assets \\
- Quality Editorial service \\
- Swift Peer Review \\
- Reprints availability \\
- E-prints Service \\
- Manuscript Podcast for convenient understanding \\
- Global attainment for your research \\
- Manuscript accessibility in different formats \\
( Pdf, E-pub, Full Text, Audio) \\
- Unceasing customer service \\
Track the below URL for one-step submission \\
https://juniperpublishers.com/online-submission.php \\
\hline
\end{tabular}

